\section{Commentary: Understanding the mitral apparatus: Still missing some pieces}

\author{
Antonio Miceli, MD, PhD
}

Ischemic mitral regurgitation (IMR) is a complex disease associated with a poor prognosis. IMR is the result of post-ischemic left ventricular remodeling, which causes displacement of papillary muscles, annular dilatation, and leaflet tethering with consequent lack of coaptation and regurgitation. ${ }^{1,2}$ The most common treatment of secondary mitral regurgitation (MR) is mitral valve annuloplasty (MVA). However, the solely reductive MVA is destined to failure over time, as it has been associated with a $66 \%$ rate of recurrent MR at 2-year follow-up. ${ }^{3}$ The high rate of failure is probably related to the subvalvular mitral dysfunction. Correction of the subvalvular apparatus has been suggested to prevent recurrence of MR. Kron and colleagues ${ }^{4}$ first pointed out the importance of relocating the posterior papillary muscle as an adjunct to standard annuloplasty. Since then, other different surgical techniques have been developed. ${ }^{5,6}$ Recently, my group and I demonstrated that concomitant papillary muscle correction compared with MVA alone is associated with 3-fold risk reduction of recurrent MR at follow-up. In addition, papillary muscle relocation is also associated with greater freedom from cardiac-related events and better positive impact on left ventricular remodeling.

In this issue of the Journal, Torkan and colleagues ${ }^{8}$ describe a new surgical technique for IMR consisting of papillary muscle relocation with a multiloop suture. Specifically, authors propose a modification of Kron and

From the Minimally Invasive Cardiac Surgery Department, Istituto Clinico Sant'Ambrogio, Milano, Italy.

Disclosures: Dr Miceli is a consultant for LivaNova.

The Journal policy requires editors and reviewers to disclose conflicts of interest and to decline handling or reviewing manuscripts for which they may have a conflict of interest. The editors and reviewers of this article have no conflicts of interest.

Received for publication Aug 24, 2020; revisions received Aug 24, 2020; accepted for publication Aug 28, 2020; available ahead of print Sept 16, 2020.

Address for reprints: Antonio Miceli, MD, PhD, Minimally Invasive Cardiac Surgery Department, Istituto Clinico Sant'Ambrogio, Via L.G. Faravelli 16, Milano, Italy (E-mail: Antoniomiceli79@alice.it)

JTCVS Techniques 2020;4:136-7

2666-2507

Copyright $(2020$ The Authors. Published by Elsevier Inc. on behalf of The American Association for Thoracic Surgery. This is an open access article under the CC BY-NCND license (http://creativecommons.org/licenses/by-nc-nd/4.0/).

https://doi.org/10.1016/j.xjtc.2020.08.072

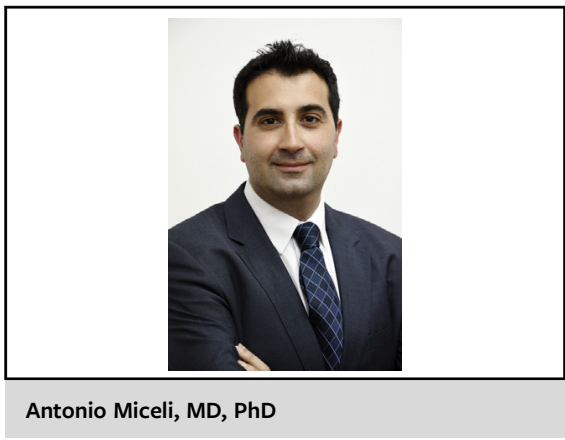

CENTRAL MESSAGE

Surgical papillary relocation with mitral valve annuloplasty is associated with better outcomes.

colleagues' technique, adopting the Leipzig loop technique described by Mohr. ${ }^{4,9}$ The procedure is interesting and potentially better than Kron's stitch, as the multiloop suture should reduce the stress on papillary tip. However, this technique presents some limitations. First, some degree of mitral valve tenting might remain in the presence of large left ventricles. In this regard, Fattouch and colleagues ${ }^{5}$ suggest relocating both papillary muscles to minimize the risk of recurrence of MR. Second, authors use a complete rigid ring 2 sizes under from the obtained measurement. Although the complete rigid ring restores the annular geometry, the mitral annulus loses its physiologic movement during cardiac cycle, especially when undersized. ${ }^{10} \mathrm{~A}$ restrictive mitral annuloplasty fixes the posterior leaflet and causes a reduction of the mitral valve opening with relative mitral stenosis under stress. ${ }^{11}$ To avoid tension on the mitral leaflets, Kron and colleagues ${ }^{4}$ recommend downsizing the annuloplasty by 1 size, whereas Fattouch and colleagues ${ }^{5}$ propose choosing a ring according to anterior leaflet length. My suggestion is to perform a lessrestrictive annuloplasty with a complete semirigid ring, which provides rigidity for annulus remodeling and maintains the flexibility during the cardiac cycle and avoids mitral stenosis. Finally, IMR is a disease of the left ventricle and papillary muscle that leads to valve dysfunction. Torkan and colleagues add evidence on the importance of addressing the problem of subvalvular apparatus in IMR. However, we need now to focus on left ventricular wall reshaping. Some external or internal ventricular-restraint devices have been developed, but more data are required. ${ }^{6}$ In conclusion, a thorough understanding of the mitral apparatus will improve the results of mitral valve repair, but to date we are still missing some pieces. 


\section{References}

1. Badhwar V, Alkhouli M, Mack MJ, Thourani VH, Ailawadi G. A pathoanatomic approach to secondary functional mitral regurgitation: evaluating the evidence. $J$ Thorac Cardiovasc Surg. 2019;158:76-81.

2. Miceli A. A thorough understanding of the mitral apparatus will improve the results of mitral valve repair. J Thorac Cardiovasc Surg. 2015;150:238-9.

3. Goldstein D, Moskowitz AJ, Gelijns AC, Ailawadi G, Parides MK, Perrault LP, et al. Two-year outcomes of surgical treatment of severe ischemic mitral regurgitation. N Engl J Med. 2016;374:344-53.

4. Kron IL, Green R, Cope JT. Surgical relocation of the posterior papillary muscle in chronic ischemic mitral regurgitation. Ann Thorac Surg. 2002;74:600-1.

5. Fattouch K, Castrovinci S, Murana G, Dioguardi P, Guccione F, Nasso G, et al. Papillary muscle relocation and mitral annuloplasty in ischemic mitral valve regurgitation: midterm results. J Thorac Cardiovasc Surg. 2014;148:1947-50.

6. Glower DD. Surgical approach to mitral regurgitation. J Am Coll Cardiol. 2012; 60:1315-22.
7. Meco M, Lio A, Montisci A, Panisi P, Ferrarini M, Miceli A, et al. Meta-analysis of results of subvalvular repair for severe ischemic mitral regurgitation. J Card Surg. 2020;35:886-96.

8. Torkan L, Servito MT, Bisleri G. Papillary muscle relocation with a multiloop suture: a proposed surgical technique for ischemic mitral regurgitation. J Thorac Cardiovasc Surg Tech. 2020;4:133-5.

9. Seeburger J, Noack T, Winkfein M, Ender J, Mohr FW. Loop technique. Multimed Man Cardiothorac Surg. 2010;2010:mmcts.2010. 004523 .

10. Di Bacco L, Miceli A. A thorough understanding of the mitral apparatus will improve the results of mitral valve repair: part 2. J Thorac Cardiovasc Surg. 2019;157:1450-1.

11. Fino C, Iacovoni A, Ferreo P, Senni M, Merlo M, Cugola D, et al Restrictive mitral valve annuloplasty versus mitral valve replacement for functional ischemic mitral regurgitation: an excercise echocardiographic study. J Cardiovasc Surg. 2014;148:447-53. 